\title{
Let's talk about pain catastrophizing measures: an item content analysis
}

\author{
Geert Crombez $^{\text {Corresp., } 1}$, Annick L De Paepe ${ }^{1}$, Elke Veirman ${ }^{1}$, Christopher Eccleston $^{2}$, Gregory Verleysen ${ }^{3}$, Dimitri \\ ML Van Ryckeghem ${ }^{1,4,5}$ \\ ${ }^{1}$ Deparment of Experimental-Clinical and Health Psychology, Faculty of Psychology and Educational Sciences, Ghent University, Gent, Belgium \\ 2 Centre for Pain Research, University of Bath, Bath, United Kingdom \\ 3 Ghent University, Research Support Office, Faculty of Psychology and Educational Sciences, Gent, Belgium \\ 4 Experimental Health Psychology, Faculty of Psychology and Neuroscience, Maastricht University, Maastricht, Netherlands \\ 5 Institute for Health and Behaviour, INSIDE, University of Luxembourg, Esch-sur-Alzette, Luxembourg \\ Corresponding Author: Geert Crombez \\ Email address: geert.crombez@ugent.be
}

Background: Concerns have been raised about whether self-report measures of pain catastrophizing reflect the construct as defined in the cognitive-behavioral literature. We investigated the content of these self-report measures, that is whether items assess the construct 'pain catastrophizing' and not other theoretical constructs (i.e. related constructs or pain outcomes) using the discriminant content validity method. Method: Items $(n=58)$ of six pain catastrophizing measures were complemented with items $(n=34)$ from questionnaires measuring pain-related worrying, vigilance, pain severity, distress and disability. Via an online survey, 94 participants rated to what extent each item was relevant for assessing pain catastrophizing, defined as "to view or present pain or painrelated problems as considerably worse than they actually are" and other relevant constructs (pain severity, pain-related worrying, vigilance, distress and disability). Results: Data were analyzed using Bayesian hierarchical models. The results revealed that the items from pain severity, pain-related worrying, vigilance, distress and disability questionnaires were distinctively related to their respective constructs. This was not observed for the items from the pain catastrophizing questionnaires. The content of the pain catastrophizing measures was equally well, or even better, captured by pain-related worrying or pain-related distress. Conclusion: Based upon current findings , a recommendation may be to develop a novel pain catastrophizing questionnaire. However, we argue that pain catastrophizing cannot be assessed by self-report questionnaires. Pain catastrophizing requires contextual information, and expert judgment, which cannot be provided by self-report questionnaires. We argue for a person-centered approach, and propose to rename 'pain catastrophizing' measures in line with what is better measured: 'pain-related worrying'. 


\section{Let's talk about pain catastrophizing measures: An}

\section{2 item content analysis}

3

4 Geert Crombez ${ }^{1, *}$, Annick L De Paepe ${ }^{1}$, Elke Veirman ${ }^{1}$, Christopher Eccleston ${ }^{2}$, Gregory

5 Verleysen $^{3}$, Dimitri ML Van Ryckeghem ${ }^{1,4,5}$

6

$7{ }^{1}$ Department of Experimental - Clinical and Health Psychology, Ghent University, Gent,

8 Belgium

$9{ }^{2}$ Centre for Pain Research, University of Bath, Bath, United Kingdom.

$10{ }^{3}$ Research Support Office, Faculty of Psychology and Educational Sciences, Ghent University,

11 Gent, Belgium

$12{ }^{4}$ Section Experimental Health Psychology, Faculty of Psychology and Neuroscience, Maastricht

13 University, Maastricht, The Netherlands

$14{ }^{5}$ Institute for Health and Behaviour, INSIDE, University of Luxembourg, Esch-sur-Alzette,

15 Luxembourg

16

17 Corresponding Author:

* Corresponding author: Geert Crombez, Henri Dunantlaan 2, B-9000 Gent, Belgium, Tel +32 9

2646461, Fax +32 926464 89, Email: Geert.crombez@,UGent.be 


\section{Abstract}

21 Background: Concerns have been raised about whether self-report measures of pain

22 catastrophizing reflect the construct as defined in the cognitive-behavioral literature. We

23 investigated the content of these self-report measures, that is whether items assess the construct

24 'pain catastrophizing' and not other theoretical constructs (i.e. related constructs or pain

25 outcomes) using the discriminant content validity method.

26 Method: Items $(n=58)$ of six pain catastrophizing measures were complemented with items

27 ( $n=34)$ from questionnaires measuring pain-related worrying, vigilance, pain severity, distress

28 and disability. Via an online survey, 94 participants rated to what extent each item was relevant

29 for assessing pain catastrophizing, defined as "to view or present pain or pain-related problems

30 as considerably worse than they actually are" and other relevant constructs (pain severity, pain-

31 related worrying, vigilance, distress and disability).

32 Results: Data were analyzed using Bayesian hierarchical models. The results revealed that the

33 items from pain severity, pain-related worrying, vigilance, distress and disability questionnaires

34 were distinctively related to their respective constructs. This was not observed for the items from

35 the pain catastrophizing questionnaires. The content of the pain catastrophizing measures was

36 equally well, or even better, captured by pain-related worrying or pain-related distress.

37 Conclusion: Based upon current findings, a recommendation may be to develop a novel pain

38 catastrophizing questionnaire. However, we argue that pain catastrophizing cannot be assessed

39 by self-report questionnaires. Pain catastrophizing requires contextual information, and expert

40 judgment, which cannot be provided by self-report questionnaires. We argue for a person-

41 centered approach, and propose to rename 'pain catastrophizing' measures in line with what is

42 better measured: 'pain-related worrying'. 


\section{1. Introduction}

44 Pain catastrophizing, broadly conceived as an exaggerated mental set brought to bear during 45 painful experiences (Sullivan et al., 2001), has emerged as one of the most important 46 psychosocial predictors of pain, distress, and disability (Edwards, Cahalan, Mensing, Smith, \& 47 Haythornthwaite, 2011; Keefe, Rumble, Scipio, Giordano, \& Perri, 2004; Quartana, Campbell, \& 48 Edwards, 2009). In a meta-analysis of 32 prospective studies, Lewis and colleagues (2015) found 49 that pain catastrophizing was the strongest predictor of persistent pain after total knee 50 arthroplasty. Sobol-Kwapinska and colleagues (2016) reviewed 53 prospective studies

51 investigating various psychosocial risk factors, and found that pain catastrophizing was most 52 strongly linked to acute postsurgical pain. In their review, Fadyl and McPherson (2008) reported 53 preliminary evidence for the role of pain catastrophizing on return to work after injury. In regard 54 to its causal status, studies investigating the processes of change in pain management programs revealed that reductions in pain catastrophizing are key for achieving treatment success (Besen, 56 Gaines, Linton, \& Shaw, 2017; Burns, Day, \& Thorn, 2012; Burns, Kubilus, Bruehl, Harden, \&

57 Lofland, 2003; Jensen, Turner, \& Romano, 2001; Smeets, Vlaeyen, Kester, \& Knottnerus, 2006; 58 Turner, Holtzman, \& Mancl, 2007). Notwithstanding these achievements, how pain catastrophizing is best measured has not

60 been adequately addressed. In an early commentary, Turner and Aaron (2001) called for an 61 inquiry to determine whether measures of pain catastrophizing really reflect the construct.

62 Despite this call for action, researchers seem to have adopted a pragmatic stance. Comforted by 63 the findings that pain catastrophizing 'makes a difference' in predicting pain, distress, and 64 disability (Illari \& Russo, 2014), researchers seem to have uncritically embraced the view that 65 pain catastrophizing questionnaires measure pain catastrophizing. We argue that this approach is 
66 flawed and deserves scrutiny. First, doubts exists whether the available questionnaires are

67 interchangeable. Indeed, although catastrophizing measures have a good test-retest reliability

68 (e.g. Wheeler, Williams, \& Morley, 2019), correlations between catastrophizing instruments are

69 often only modest (e.g. Goubert, Crombez, \& Danneels, 2005). Second, catastrophizing is a

70 transdiagnostic construct (Gellatly \& Beck, 2016; Linton, 2013), and an essential ingredient in

71 many models of psychopathological disorders (Beck, 1979; Clark, 1986; Salkovskis \& Clark,

72 1993). Concerns have been raised about whether catastrophizing as discussed in the pain field is

73 faithful to how it is used in the psychopathology literature (Flink, Boersma, \& Linton, 2013;

74 Neblett, 2017; Turner \& Aaron, 2001). Historically, catastrophizing was introduced by Ellis

75 (1962) and picked up by Beck (1976), who argued that neurosis and emotional disorders are

76 caused by irrational or exaggerated thought patterns, such as catastrophic thinking.

77 Catastrophizing was considered as repeated thinking that a situation is unbearable or terrible

78 when it is just a nuisance (Ellis, 1962), or as a dwelling on the most extreme negative

79 consequences conceivable (Beck, 1976). At the core of these definitions is the idea that a person

80 "views or presents a situation as considerably worse than it actually is"

81 (https://en.oxforddictionaries.com/definition/catastrophize accessed on 30/09/2016). Third, pain

82 catastrophizing questionnaires should be distinct from questionnaires assessing other theoretical

83 constructs (e.g. pain vigilance, pain-related worry, or fear), and from primary outcomes (e.g. pain

84 severity, pain-related distress, or pain-related disability; Hirsh, George, Riley, \& Robinson,

85 2007). Otherwise, theory building becomes hazardous (Dixon \& Johnston, 2019; Goubert,

86 Crombez, \& Van Damme, 2004; Wideman, Adams, \& Sullivan, 2009) and the explanatory

87 power of pain catastrophizing may be inflated. 

catastrophizing measures are (a) relevant for the construct 'pain catastrophizing' (content validity), and (b) distinct from related constructs (i.e., 'worrying about pain', 'pain vigilance'), and primary outcomes (i.e., 'pain severity', 'pain-related distress', and 'pain-related disability') (discriminant content validity).

\section{Materials \& Methods}

2.1. Participants

Participants were recruited via Prolific (https://www.prolific.ac/), a recruitment

application to attract participants for online studies (Peer, Brandimarte, Samat, \& Acquisti,

97 2017). Inclusion criteria for participation in the survey were: (1) being 18 years of age or older,

98 (2) having English as a first language, and (3) having access to an internet-enabled device.

99 Furthermore, data from participants were only used for the statistical analyses when participants

100 were able to complete the online assessment in line with given instructions (performance

101 criteria), and took at least 15 minutes to complete the assessment.

2.2. Discriminant Content Validity method

The Discriminant Content Validity (DCV) method provides a quantitative procedure for assessing the content of theory-based measures (for a detailed overview of the methodology, see Bell, Johnston, Allan, Pollard \& Johnston, 2017; Johnston et al., 2014)). We describe the DCV in

1065 steps.

2.2.1. Step 1: Identification of constructs

Six constructs were identified to be used for the categorization of the items. These constructs were 'pain catastrophizing', 'worrying about pain', ‘pain vigilance', 'pain severity',

110 'pain-related distress', and 'pain-related disability'. The constructs 'worrying about pain' and 
111 'pain vigilance' were selected to investigate to what extent items of pain catastrophizing

112 questionnaires could be clearly differentiated from items of other separate, but theoretically

113 related constructs. The categories 'pain severity', 'pain-related distress' and 'pain-related

114 disability' were selected to investigate to what extent items of pain catastrophizing

115 questionnaires could be clearly differentiated from items of pain outcomes. In the case of

116 insufficient discriminative validity of pain catastrophizing questionnaires or content overlap,

117 research findings about pain catastrophizing may be inflated or confounded. Finally, an 'other'

118 category was added to prevent the impression that all items had to be categorized as measures of

119 one of the six predefined constructs. At the same time, the 'other' category provided the

120 opportunity to check whether participants understood/followed the given instructions. In

121 particular, we considered it impossible for participants to provide the same extreme scores (i.e., -

12210 or +10 ) for an item on all six constructs and the 'other' category. In that respect, the 'other'

123 category is redundant and scores of the 'other' category were not included in the statistical

124 analyses.

125 2.2.2. Construct definitions

126 For each of the identified constructs, a definition was formulated. Some of the constructs

127 were, however, considered self-explanatory (e.g. 'pain severity', 'pain-related distress') and no

128 detailed definition was given. For other constructs, there were multiple definitions available. To

129 avoid the introduction of bias in our findings due to preferring the definition of one theoretical

130 framework over another, we opted to use common language definitions as provided in the Online

131 Oxford Living Dictionaries for English (https://en.oxforddictionaries.com accessed on

132 30/09/2016). Where necessary, we adapted these definitions to the context of pain. This resulted

133 in the following definitions: (1) pain catastrophizing: 'To view or present pain or pain-related 
134 problems as considerably worse than they actually are'; (2) worrying about pain: 'To feel

135 troubled or anxious about actual or potential pain or pain-related problems'; (3) pain vigilance:

136 'The action or state of keeping careful watch for possible pain'; (4) pain-related distress:

137 'Distress related to pain or pain-related problems'; (5) pain-related disability: 'Being limited in

138 your movements, senses, or activities due to pain'; and (6) pain severity: 'The intensity or

139 severity of pain'. For the 'other' category the following description was provided: 'The item does

140 not measure any of the previous constructs'.

141 2.2.3. Selection of pain catastrophizing items

142 A database was created of all items of available self-report measures assessing pain

143 catastrophizing. Items were included when the questionnaire fulfilled the following criteria: (1)

144 used as part of empirical study indexed in the Web of Science, (2) available in English, and (3)

145 consisting of a (sub-)scale explicitly developed for the assessment of pain catastrophizing in

146 adults. A literature search resulted in 10 potentially relevant questionnaires. We contacted the

147 authors of these questionnaires as well as other key authors $(n=19)$ in the field of pain to ask for

148 more information on (one of) these questionnaires, and a copy of these questionnaires whenever

149 we did not yet have a copy. In addition, we asked these authors whether they were aware of other

150 pain catastrophizing questionnaires that we might have overlooked. The search for pain

151 catastrophizing instruments was performed during October-November 2016. Of all retrieved

152 questionnaires, some were excluded for the following reasons: (1) No article has been published

153 using the instrument (i.e., the 'Catastrophizing Thoughts about Pain Scale', and the 'Catastrophic

154 Interpretation of Pain Scale'), (2) The instrument was relabeled in a later development phase

155 (i.e., the 'Catastrophizing Thoughts about Pain Scale' was relabeled as the 'Worry About Pain

156 Questionnaire'), (3) No English version of the questionnaire was available (i.e., the 'Pijn Coping 
157 en Cognitie Lijst'), and (4) a standard item format was not used: The 'Cognitive Errors

158 Questionnaire' (Lefebvre, 1981) used brief vignettes describing specific situations participants

159 may experience. In addition, the 'Coping met Pijn Vragenlijst' was not included because the

160 items were very similar to the 'Coping Strategies Questionnaires'. Finally, six measures of 'pain

161 catastrophizing' were included in the content analysis:

162 - The catastrophizing subscale (three items, e.g. "When I become aware of my pain, this

163 thought comes through my head: I can't have a tumour, can I?") of the Avoidance

164 Endurance Questionnaire (AEQ; Hasenbring, Hallner, \& Rusu, 2009).

165 - The catastrophizing subscale (10 items ${ }^{1}$, e.g. "I begin to worry that something might be

166 seriously wrong with me") of the Cognitive Coping Strategies Inventory (CCSI; Butler,

167 Damarin, Beaulieu, Schwebel, \& Thorn, 1989).

- The catastrophizing subscale (17 items, e.g. "I am disappointed in myself for giving in to the pain") of the Pain Cognition List (PCL; Vlaeyen et al., 1990).

- The Pain Catastrophizing Scale (13 items, e.g. “When I feel pain, I feel like I can't go on"; Sullivan et al., 1995).

- The catastrophizing subscale (nine items, e.g. "This pain drives me crazy") of the PainRelated Self-Statements Scale (PRSS; Flor, Behle, \& Birbaumer, 1993).

- The catastrophizing subscale (six items, e.g. "When I feel pain, I feel I can't stand it anymore") of the Coping Strategies Questionnaire (CSQ; Rosenstiel \& Keefe, 1983). In order to minimize the task load on participants, items were removed from the final 177 database in case of content overlap. This was the case for five items of the CSQ, which were almost identical to items of the PCS. The final database contained 53 items, of which three were

\footnotetext{
${ }^{1}$ Two items (i.e., "I imagine the pain becoming even more intense and hurtful" and "I tell myself that I don't think I can bear the pain any longer") of the catastrophizing subscale of the CCSI were erroneously not included in the content analysis
} 
179 reverse coded items (e.g. PCL: "Thinking too much about the pain only makes it worse"). The 180 set of catastrophizing items used can be found in Table S1.

181 2.2.4. Selection of items for the other constructs

182 Items for the contrast constructs 'worrying about pain', 'pain vigilance', 'pain severity', 183 'pain-related distress', and 'pain-related disability' were selected from subscales that were 184 considered appropriate for the respective construct. For feasibility reasons, the number of items 185 for each construct was limited. For 'worrying about pain', nine items (e.g. 'I wonder about the cause of the pain") were retrieved from the Pain Cognitions Inventory (PCI; Kraaimaat, Bakker 187 \& Evers, 1997). For 'pain vigilance', ten items (e.g. "I pay close attention to pain”) were retrieved from the vigilance scale of the Pain Vigilance and Awareness Questionnaire (PVAQ; McCracken, 1997). For 'pain severity', three items (e.g. “On the average, how severe has your pain been during the last week") were retrieved from the pain severity subscale of the Multidimensional Pain Inventory (MPI; Kerns, Turk, \& Rudy, 1985). For 'pain-related distress', three items (e.g. "During the past week, how tense or anxious have you been") were retrieved from the affective distress subscale of the MPI (Kerns et al., 1985). For 'pain-related disability', nine items (e.g. "How much has your pain changed your ability to participate in recreational and other social activities") were retrieved from the disability subscale of the MPI (Kerns et al., 1985). This database contained 34 items, of which three items were reverse coded items (e.g.

197 PVAQ: "I find it easy to ignore pain”).

\subsubsection{Rating scale of items}

Similar to the procedure of Johnston and colleagues (Johnston et al., 2014), participants 
202 particular construct ('yes' or 'no'). In the second question, participants rated to what extent they

203 were confident in their judgment using an 11 point scale $(0=0 \%$ confidence to $10=100 \%$

204 confidence). For 'yes'-responses the confidence score remained a positive value, whereas for

205 'no'-responses the confidence score was turned into a negative value. As such, outcome scores

206 could range between -10 and +10 .

207 2.3. Self-report measures

208 2.3.1. Participant characteristics

209 Participants were asked to provide demographic information including date of birth, 210 gender, first language, country of residence, ethnicity, marital status, profession, level of

211 education and health status (ranging from $1=$ excellent health to $5=$ poor health).

212 2.3.2. Graded Chronic Pain Scale

213

Pain severity of the participants was assessed with the Graded Chronic Pain Scale

214 (GCPS, Von Korff, Ormel, Keefe, \& Dworkin, 1992). The GCPS consists of seven items: (1)

215 pain intensity right now; (2) worst pain intensity over the last six months; (3) average pain

216 intensity over the last six months; (4) limitation in daily activities because of pain; (5) limitation

217 in recreational, social, and family activities within the last six months; (6) limitation in the ability

218 to work because of pain within the last six months; and (7) the number of days disabled within

219 the last six months. All items, except for the number of days disabled, are scored on an 11-point

220 scale (0-10). Following guidelines provided by Von Korff et al. (1992), participants were

221 categorized into one of five grades: grade 0 ('pain free'), grade 1 ('low disability-low intensity'),

222 grade 2 ('low disability-high intensity'), grade 3 ('high disability-low intensity'), and grade 4

223 ('high disability-high intensity'). Research indicated that this questionnaire is reliable and valid 
224 for assessing pain and disability in general populations (Von Korff et al., 1992; Goubert,

225 Crombez \& De Bourdeaudhuij, 2004, Dixon, Pollard \& Johnston, 2007).

226

227

228

229

230

231

232

233 234 2012).

235

236

237

238

239

240

241

242

243

244

245

246

\subsubsection{Detection of careless responding}

Two strategies were used to detect careless responding (Meade \& Craig, 2012). First, three items from the Instructional Manipulation Check (IMC, e.g. "It's important that you pay attention to this study. Please tick 'yes' and '30\%' for all definitions") were intermixed with the DCV items (see also Oppenheimer, Meyvis, \& Davidenko, 2009). Second, participants were asked to indicate their level of attention during the online survey $(1=$ almost no attention; $2=$ very little attention; $3=$ some of my attention; $4=$ most of my attention; $5=$ my full attention), and whether, in their honest opinion, we should use their data ("yes or no"; Meade \& Craig,

\subsection{Procedure}

The study was performed in line with the ethical guidelines of the Ethics Review Panel of the University of Luxembourg. The online survey was constructed using LimeSurvey 2.00 and a link to the survey was distributed via Prolific Academic. After opening the Web page and formally giving informed consent (online), participants were provided with the instructions of the DCV method, and two non-related examples on how the DCV can be completed. Participants were provided with one of three item sets. The final set of 87 items (excluding IMC items) was split into three item sets because piloting revealed that participants became fatigued when they attempted to categorize too many items. Each item set contained a random selection of items (stratified randomization on questionnaire) and one shared item drawn from each questionnaire (version 1: 25 unique +11 shared items; version 2: 25 unique +11 shared items; version 3: 26 unique +11 shared items). In addition, three IMC items were added to each version. The order of 
247 item presentation was random for each participant. Also, the order of presentation of the

248 constructs, listed above each question, differed between participants (three possible orders which

249 remained consistent throughout a person's assessment). After participants completed the DCV

250 questions, they gave their demographic information, and answered questions assessing their pain

251 (GCPS) and questions to detect careless responding. The online assessment lasted a mean of 35.4

252 minutes $(S D=15.8)$. Participants were rewarded two English pounds for participation.

253 2.5. Statistical analysis

254 Results were analyzed using Bayesian hierarchical models (JAGS version 4.3.0) in R

255 version 3.6.0 (R Core Team, 2019) to ensure that estimates did not fall outside the actual

256 response range [-10 to 10]. In the model a different mu parameter was estimated for each

257 construct or measure, depending on the research question (see below). In addition, a random

258 effect for subject and item was added. All parameters received vague priors (normal distributions

259 with a very large standard deviation) in order to let the data speak for itself. The dependent

260 variable was the DCV outcome score (ranging from -10 to 10). The mu parameters come from a

261 truncated normal distribution $[-10,10]$ so the credibility intervals only contain sensible values.

262 To generate the posterior samples, we used 4 chains with 20000 iterations each, 5000 being

263 discarded as burn in. Traceplots and Rhat values of 1 indicated that all the chains for the mu

264 parameters reached convergence. Because participants reported difficulties in scoring the reverse 265 coded items, these items were excluded from all analyses.

266 First, as a manipulation check we investigated whether the items from questionnaires

267 assessing 'pain catastrophizing', 'worrying about pain, 'pain vigilance', 'pain severity', 'pain-

268 related distress', and 'pain-related disability', were indeed most relevant for measuring their 
269 respective construct. Separate analyses were run for each measure. A Bayesian hierarchical

270 model was fitted with construct as a fixed effect and subject and item as random effects.

271 Second, to identify which catastrophizing questionnaires scored highest on 'pain

272 catastrophizing', we investigated the effect of measure (AEQ, CSQ, CSSI, PCL, PCS, and

273 PRSS) on the outcome scores for the construct 'pain catastrophizing' only. A Bayesian

274 hierarchical model was fitted with measure as a fixed effect and subject and item as random 275 effect.

276

Third, we investigated to what extent items of each pain catastrophizing measure were

277

278

279

280

281

282

283

284

285

286

287

288

289

290 rated to be distinctively associated with the construct of pain catastrophizing, and less to the other constructs. For each pain catastrophizing questionnaire a separate Bayesian hierarchical model was fitted, comparing the score for the construct 'pain catastrophizing' to those for the five other constructs ('worrying about pain', 'pain vigilance', 'pain severity', 'pain-related distress', and 'pain-related disability'). The models contained construct as a fixed effect and subject and item as random effects.

Finally, a separate Bayesian hierarchical model was fitted for each item of the pain catastrophizing questionnaires. The models included construct as a fixed effect and subject as a random effect. For all models, significance was evaluated at the 5\% significance level (twosided). Estimated mu parameters $(\hat{\mu})$ and their associated $95 \%$ credibility intervals $(\mathrm{CI})$ are reported.

\section{Results}

3.1. Participants 

section 2.1), 44 participants were excluded from further analyses. More specifically, one

293 participant failed to respond correctly on the IMC items, 36 participants provided unreliable data 294 (i.e., at least one item was scored as -10 or +10 for all constructs), two participants stated that 295 English was not their first language, four participants completed the questionnaire in less than 15 296 minutes, and one participant indicated at the end of the questionnaire that his/her data should not 297 be used. The final sample contained 94 participants (mean age of 36 years, $S D=12 ; 59$ males). 298 Most participants reported their ethnicity as Caucasian $(n=87,93 \%)$. Many participants were 299 single $(n=39,41 \%)$ or living with a partner $(n=41,44 \%)$. The majority were from the United 300 Kingdom $(n=55,59 \%)$ followed by the United States $(n=28,30 \%)$. Sixty-nine participants 301 followed or were following a university (college) program (73\%).

302 The large majority of participants $(n=76,81 \%)$ were in at least good health (excellent 303 health: $n=14(15 \%)$; very good health: $n=34$ (36\%); good health: $n=28(30 \%)$; fair health: $n=$ $30412(13 \%)$; poor health: $n=6(6 \%))$. On the GCPS, participants' mean current pain was $2.22(S D$ $305=2.20 ;$ median $=2, \mathrm{IQR}=3$ ). Participants' mean worst pain level during the past six months and 306 mean average pain level were $5.05(S D=2.99$; median $=5, \mathrm{IQR}=5)$ and $3.48(S D=2.67$;

307 median $=3, \mathrm{IQR}=5$ ), respectively. Furthermore, participants reported a mean pain interference 308 with daily activities of $2.98(S D=2.98$; median $=2, \mathrm{IQR}=5.75)$, a mean change of their ability 309 to take part in recreational, social and family activities of $2.80(S D=2.95$; median $=2, \mathrm{IQR}=5)$, 310 and a mean change of their ability to work of $2.55(S D=2.92$; median $=1.5, \mathrm{IQR}=5)$. Finally, 311 participants reported a mean of 15 days off normal task $(S D=32$; median $=3, \mathrm{IQR}=10)$.

312 Calculation of the pain grade showed that few participants were classified in grade $0(n=8,8 \%)$. 
313 Most participants were classified in grade $1(n=56,60 \%)$. Six participants were classified in

314 grade $2(6 \%), 13$ participants in grade $3(14 \%)$, and 11 participants in grade $4(12 \%)$.

315 3.2. Content validity of alternative constructs

316 As a manipulation check, we investigated whether the items from questionnaires assessing

317 'worrying about pain' (PCI), 'pain vigilance' (PVAQ), 'pain severity' (MPI - pain severity

318 subscale), 'pain-related distress' (MPI - affective distress subscale), and pain-related disability

319 (MPI - disability subscale) were indeed most relevant for measuring their respective construct.

320 Findings are displayed in Figure 1. Overall, participants have performed the DCV method

321 adequately. Almost all measures loaded highest and distinctively on their respective construct.

322 There was one exception, i.e. participants were unable to differentiate between items of

323 'worrying about pain' and items of 'pain-related distress'. More detailed results are given in 324 supplementary information (S1 file).

325

326

Figure 1 about here

327

328 3.3. Content analyses of pain catastrophizing measures

329

3.3.1. Content analyses between pain catastrophizing measures

330

To identify which catastrophizing measures scored highest on 'pain catastrophizing', we 331 investigated the effect of measure (AEQ, CSQ, CSSI, PCL, PCS, PRSS) on the outcome scores

332 for the construct 'pain catastrophizing' only. The estimated mu parameters and the $95 \%$

333 credibility intervals for each measure on 'pain catastrophizing' are displayed in Figure 2. The

334 CSQ had the highest score on the construct 'catastrophizing'. The AEQ had the second highest

335 score and did not score significantly lower than the CSQ ( $\Delta=0.13,95 \%$ CI [-1.25 to 1.52$])$. The 
336 CCSI, the PRSS, the PCS and the PCL scored significantly lower than the AEQ and the CSQ.

337 The items of the AEQ, CSQ, CCSI, PCS and PRSS scored on average significantly higher than 0

338 on the construct of pain catastrophizing. The items of the PCL scored significantly lower than 0 ,

339 indicating that participants believed that the items did not measure pain catastrophizing.

340 In summary, there is variability in the extent to which instruments measure pain

341 catastrophizing. The AEQ (Hasenbring et al., 2009) and the CSQ (Rosenstiel \& Keefe, 1983)

342 have the highest ratings for the pain catastrophizing construct. Participants did not endorse the

343 PCL (Vlaeyen et al., 1990) as measuring pain catastrophizing.

344

345

346

347

348

349

350

351

352

353

354

355

356

357

358

Figure 2 about here

\subsubsection{Content analyses per pain catastrophizing measure}

In this section, we investigated to what extent items of each pain catastrophizing measure were rated to be distinctively associated with the construct 'pain catastrophizing', and less to the other constructs. For each catastrophizing questionnaire, a different model was fit, comparing the score for the construct 'pain catastrophizing' to those for the five other constructs ('worrying about pain', 'pain vigilance', ‘pain severity', 'pain-related disability', and 'pain-related distress'). Figure 3 displays the estimated mu parameters for each construct and their $95 \%$ credibility intervals per measure of pain catastrophizing.

$A E Q$. The items of this measure scored significantly higher on 'pain catastrophizing' than on 'pain-related disability' $(\Delta=10.41,95 \%$ CI [9.06 to 11.78$])$, 'pain severity' $(\Delta=8.64,95 \%$ CI [7.28 to 10.00$])$, and 'pain vigilance' $(\Delta=6.65,95 \%$ CI [5.30 to 8.01$])$. However, the items scored significantly lower on 'pain catastrophizing' than on 'worrying about pain' $(\Delta=-1.68$, 
$35995 \% \mathrm{CI}[-3.01$ to -0.32$])$. There was no significant difference with the score on "pain-related 360 distress' $(\Delta=0.58,95 \%$ CI $[-0.78$ to 1.94$])$.

361 CSQ. The items of this measure scored significantly higher on 'pain catastrophizing' than 362 on 'pain-related disability' ( $\Delta=6.25,95 \% \mathrm{CI}[5.14$ to 7.37$])$, 'pain severity' $(\Delta=2.29,95 \% \mathrm{CI}$

363 [1.19 to 3.41]), and 'pain vigilance' ( $\Delta=8.23,95 \%$ CI [7.12 to 9.34]). Yet, the items scored

364 significantly lower on 'pain catastrophizing' than on 'pain-related distress' ( $\Delta=-2.93,95 \%$ CI [3654.04 to -1.82$])$. There was no significant difference with the score on 'worrying about pain' $(\Delta=$ 366 $0.30,95 \%$ CI [-0.81 to 1.41$])$.

367

CCSI. The items of this measure scored significantly higher on 'pain catastrophizing' than 368 on 'pain-related disability' $(\Delta=8.27,95 \%$ CI [ 7.25 to 9.30$])$, 'pain severity' $(\Delta=4.33,95 \% \mathrm{CI}$ [3.30 to 5.37]), and 'pain vigilance' ( $\Delta=5.03,95 \% \mathrm{CI}$ [4.00 to 6.07$])$. However, the items 370 scored significantly lower on 'pain catastrophizing' than on 'worrying about pain' $(\Delta=-1.12$, 95\% CI [-2.15 to -0.09]). There was no significant difference with the score on 'pain-related 372 distress' $(\Delta=-0.81,95 \%$ CI [-1.86 to 0.22$])$.

PRSS. The items of this measure scored significantly higher on 'pain catastrophizing' than on 'pain-related disability' $(\Delta=4.66,95 \%$ CI [3.61 to 5.71]) and 'pain vigilance' ( $\Delta=5.20,95 \%$ CI [4.14 to 6.25]). However, the items scored significantly lower on 'pain catastrophizing' than on 'pain-related distress' $(\Delta=-1.91,95 \%$ CI [-2.96 to -0.86$])$. There was no significant 377 difference with the score on 'pain severity' ( $\Delta=-0.90,95 \%$ CI [-1.94 to 0.14$])$ and 'worrying 378 about pain' $(\Delta=0.10,95 \%$ CI $[-0.95$ to 1.15$])$.

PCS. The items of this measure scored significantly higher on 'pain catastrophizing' than 380 on 'pain-related disability' $(\Delta=5.12,95 \%$ CI $[4.28$ to 5.98$])$ and 'pain vigilance' $(\Delta=3.77,95 \%$ 
382 on 'pain-related distress' ( $\Delta=-4.74,95 \%$ CI [-5.60 to -3.89$])$ and 'worrying about pain' ( $\Delta=-$

$3833.90,95 \% \mathrm{CI}[-4.76$ to -3.05$])$. There was no significant difference with the score on 'pain

384 severity' $(\Delta=0.82,95 \% \mathrm{CI}[-0.03$ to 1.67$])$.

$385 P C L$. The items of this measure scored significantly higher on 'pain catastrophizing' than 386 on 'pain-related disability' ( $\Delta=1.55,95 \% \mathrm{CI}[0.73$ to 2.38$]$ ), albeit that the score on 'pain 387 catastrophizing' was negative. Moreover, the items scored significantly lower on 'pain 388 catastrophizing' than on 'pain-related distress' $(\Delta=-3.87,95 \%$ CI [-4.68 to -3.04$])$ and 389 'worrying about pain' $(\Delta=-3.91,95 \% \mathrm{CI}[-4.73$ to -3.09$])$. There was no significant difference 390 with the score on 'pain severity' $(\Delta=-0.06,95 \%$ CI [ -0.87 to 0.75$])$ and 'pain vigilance' ( $\Delta=$ 391 $0.58,95 \% \mathrm{CI}[-1.40$ to 0.24$])$.

In summary, none of the six instruments of pain catastrophizing distinctively assessed 393 'pain catastrophizing'. Most instruments have content that was equally well, or even better 394 captured by the constructs 'worrying about pain' or 'pain-related distress'.

395

396

397

398

400

401

402

403

404

Figure 3 about here

\subsubsection{The five highest and lowest scoring pain catastrophizing items}

The results of the five items with the highest and lowest scores on the construct 'pain catastrophizing' are reported here. A complete list detailing the performance of each item per construct is presented in Table S1. A separate model was fitted for each of the items. Results for the five highest and lowest scoring pain catastrophizing items are summarized in Table 1 . The five highest scoring items had good positive mean item scores ( $>5.00)$, indicating that these items were endorsed to measure 'pain catastrophizing'. However, these items did not 
405 distinctively measure 'pain catastrophizing'. These items were also found to load equally well, or 406 even better on 'worry about pain', or 'pain-related distress'. The five lowest scoring items had 407 negative item scores, indicating that these items were considered not to measure 'pain 408 catastrophizing'.

409 In summary, none of the five highest scoring items of the pain catastrophizing instruments 410 distinctively assessed 'pain catastrophizing'. They have content that was equally well, or even 411 better, captured by the constructs 'worrying about pain' or 'pain-related distress'. The five 412 lowest scoring items did not seem to have any content related to 'pain catastrophizing'.

415 3.4. Additional analyses - influence of item set group and moderators In a series of additional analyses, we checked whether participants from the three item set 417 groups were comparable with respect to their scores. Item set group did not moderate the outcome 418 score for the shared items on the different constructs. These groups did not differ with respect to 419 potentially moderating variables (pain group, age and gender). Therefore, item set group was not 420 considered as a fixed effect in the analyses.

422 between the constructs and the score allocated to the items. The overall pattern of results did not 423 differ as a function of pain group, age, and gender. Detailed results of these additional analyses 424 are available in supplementary information (S2 File). 


\section{4. Discussion}

428

429

430

431

432

433

434

435

436

437

438

439

440

441

442

443

444

445

446

447

448

449

This study investigated the content of pain catastrophizing measures. Participants rated the extent to which each item was relevant for measuring 'pain catastrophizing', other theoretically related constructs ('worrying about pain', 'pain vigilance') and pain outcome constructs ('pain severity', 'pain-related distress', and 'pain-related disability'). The results can be readily summarized. First, there was variability in the extent to which instruments measure 'pain catastrophizing'. The item content of the AEQ (Hasenbring et al., 2009) and the CSQ (Rosenstiel \& Keefe, 1983) best reflected 'pain catastrophizing’. Second, despite some instruments measure 'pain catastrophizing' better than others, none of the instruments purporting to measure pain catastrophizing, distinctively assessed 'pain catastrophizing'. Most instruments had content that was equally well, or was even better, captured by the constructs of 'worrying about pain' or 'pain-related distress'. Third, this pattern was robust. It did not substantially differ between individuals reporting disabling pain, and it was also observed for the five items assigned the highest values for 'pain catastrophizing'. Current findings confirm the doubts raised about whether pain catastrophizing measures actually assess 'pain catastrophizing' as defined in the cognitive-behavioral literature (Eccleston \& Crombez, 2017; Eccleston, Fisher, Vervoort, \& Crombez, 2012; Turner \& Aaron, 2001).

To our knowledge, this study is the first to empirically investigate the content of pain catastrophizing instruments, addressing the extent to which items are relevant for the construct 'pain catastrophizing' and to what extent these items are distinct from other related constructs and pain outcome constructs. Despite being an essential property of an instrument (Terwee et al., 2007), content validity is often neglected and overlooked at the expense of other forms of validity such as construct and criterion validity (Dixon \& Johnston, 2019; Wiering, Boer, \& 
450 Delnoij, 2017). Furthermore, content validity is often confused with face validity (i.e. the extent 451 to which an instrument appears to be valid), which is technically not a form of validity

452 (Lilienfeld, Pydych, Lynn, Latzman, \& Waldman, 2017). With the advent of patient-reported 453 outcomes, various guidelines for designing new instruments are available and increasingly used 454 (Magasi et al., 2012). These provide guidance for ensuring and assessing content validity. Here, 455 we addressed the content validity of already available instruments. Such an approach is helpful 456 in identifying and highlighting measurement and conceptual problems with established 457 instruments, which are too often taken for granted to be valid (Crombez, 2015; Fried, 2017; 458 Grossman, 2011; Lauwerier et al., 2015). Adopting the Oxford Living dictionary definition, we 459 defined 'pain catastrophizing' as 'to view or present pain or pain-related problems as 460 considerably worse than they actually are". This definition is in line with how the construct is 461 used in psychopathology. Furthermore, many studies on pain catastrophizing seem to adhere to 462 this meaning. For example, Sobol-Kwapinska and colleagues (2016) discussed pain 463 catastrophizing as exaggerating the negative aspects of a situation. Similarly, in their critical 464 review of pain catastrophizing, Quartana and colleagues (2009) defined pain-related 465 catastrophizing as "a set of exaggerated and negative cognitive and emotional schema brought to 466 bear during actual or anticipated painful stimulation" (p. 2).

467 The results of current content analysis are sobering. None of the six instruments 468 distinctively measured 'pain catastrophizing'. Similar analyses at the item level corroborated this 469 finding. Further, instruments purporting to measure 'pain catastrophizing' were considered to 470 perform equally well, or even better in their ability to assess 'worrying about pain'. This may not 471 come as a surprise. Many authors consider pain catastrophizing as an extreme instance of 472 worrying (Davey \& Levy, 1998; Harvey \& Greenall, 2003). It then makes sense that worrying 
473 and catastrophizing are strongly intertwined. An identical pattern was found for 'pain

474 catastrophizing' and 'pain-related distress'. Such a strong overlap was not expected.

475 Theoretically, pain catastrophizing is a precursor of pain-related distress (Rode, Salkovskis, \&

476 Jack, 2001; Vlaeyen \& Linton, 2000). We anticipated that cause and effect would be

477 distinguishable. This was not observed. Reconsidering the literature, Beck (1976) and Ellis

478 (1962) identified catastrophizing as part of clinical forms of distress and anxiety. Also, Hirsch

479 and colleagues (2007) came to the same conclusion after showing that pain catastrophizing did

480 offer little predictive value beyond negative mood.

481 We recognize that our conclusion that measures of pain catastrophizing actually do not

482 measure 'pain catastrophizing', as understood by our participants, is a major challenge to models

483 that hold pain catastrophizing as a core concept. We were, however, careful to ensure that our

484 results are internally valid. We checked whether participants correctly performed the task. Also,

485 we showed that our method for assessing content validity worked for instruments measuring

486 other constructs (i.e. 'worrying about pain', vigilance', and 'pain severity'). In contrast to the

487 items from the pain catastrophizing measures, the items of these instruments had fidelity. Only

488 'pain-related distress' and 'pain-related worrying' were strongly interrelated. We also

489 investigated whether different results emerged as a function of age, gender and pain status.

490 Overall, the pattern of results, remained the same. The few significant moderation effects

491 observed, were not compelling and did not lead to alternative interpretations.

492 A natural response to our results may be to embark on developing a novel questionnaire.

493 This seems appropriate at first sight. Our database of items may be a good starting point, and

494 new items that comprehensively reflect facets of 'pain catastrophizing' may be designed. Also,

495 guidelines for instrument development are available (Bossuyt et al., 2015; DeWalt, Rothrock, 
496 Yount, Stone, \& Group, 2007). However, we argue that pain catastrophizing, defined as "to view

497 or present pain or pain-related problems as considerably worse than they actually are", cannot be

498 assessed by self-report measures. At the heart is a measurement issue common in psychology.

499 Instruments with discriminative ambitions (Kirshner \& Guyatt, 1985), such as pain

500 catastrophizing questionnaires, need a reference standard to substantiate their diagnostic test

501 accuracy (Bossuyt et al., 2015). For catastrophizing, this means establishing that someone's

502 belief about pain or pain-related problems is incorrect or exaggerated. To judge such an error,

503 one needs three things: an objective measure of the actuality ('how bad things really are'); the

504 population standard for worrying about pain ('how bad everyone else think they are'); and an

505 expert judgment that the individual's perception crosses the threshold into extreme ('it is not as

506 bad as they believe'). Even when one can measure the extent of a real catastrophe, and if

507 population standards for worrying about pain were established, somebody will always have to

508 decide whether the experience of a person is worse than the situation demands. Such decisions

509 require contextual information, which self-report instruments do not provide. In summary, we do

510 not think it is possible to measure pain catastrophizing using self-report questionnaires.

511 Therefore, we propose to adopt a person-centered approach, and to rename 'pain catastrophizing'

512 measures in line with what is better measured: 'pain-related worrying' (Eccleston \& Crombez,

513 2017; Eccleston et al., 2012). Such renaming may also have clinical implications. It may invite

514 clinicians to explore what patients are worried about. In contrast, the label 'pain catastrophizing'

515 may easily elicit inappropriate referral to mental health professionals with expertise in abnormal

516 and extreme cognition and affect, leaving patients feeling less understood and more stigmatized

517 (Amtmann et al., 2018; De Ruddere \& Craig, 2016). 
519 measure pain catastrophizing have proven to be empirically useful in predicting and explaining a

520 range of outcomes. Indeed, a change in name does not change the successes that have been

521 achieved with these questionnaires. To improve the theory that emerges from this successful

522 empiricism we suggest the following. First, we propose to always look beyond the aggregate

523 scores of instruments, and to unpack instruments to their basic constituents (Eccleston \&

524 Crombez, 2017). That way, we may find (dis)similarities with other constructs, and identify the

525 critical components in an explanatory model of pain, distress and disability. Some of these

526 components may relate to repetitive negative thinking (Davey \& Levy, 1998; Flink et al., 2013),

527 appraisal (Sullivan et al., 2001), expectancies about future pain and disability (Peerdeman, van

528 Laarhoven, Peters, \& Evers, 2016), cognitive intrusion (Attridge, Crombez, Van Ryckeghem,

529 Keogh, \& Eccleston, 2015), or personal inadequacies (Davey \& Levy, 1998). Second, if

530 researchers truly want to investigate the causal role of psychological variables in predicting pain,

531 pain-related distress and disability, we need to carefully check and appropriately control for

532 confounding factors. Here, we found content overlap with relevant pain outcomes, in particular

533 pain-related distress. We recommend that in future studies on the role of psychosocial variables,

534 content overlap with outcomes is systematically addressed. The DCV method used here can be

535 easily adopted (Dixon \& Johnston, 2019).

536 Our findings are limited by the methods we chose. First, the content validity was

537 investigated using people willing and able to participate in an online study. No experts or

538 patients were involved. Second, we opted for a quantitative analysis of content validity. Other

539 methods are possible, and may provide insight about how exactly participants understand items

540 (Amtmann et al., 2018). One promising procedure, for example, is cognitive interviewing 
541 (Beatty \& Willis, 2007; Willis, 2015). Third, we adopted the DCV method (Johnston et al.

542 2014), but our statistical analyses differed. Their research with the DCV method involves a low

543 number of participants, and uses primarily one-sample or paired t-tests. Hence, their results

544 strongly depend on sample size and statistical power. Our approach for content validity involves

545 analyses using Bayesian hierarchical models, which requires a larger number of participants.

546 Notwithstanding this, it has several advantages (e.g. combined analyses on item and measure

547 level, group and construct comparisons, and confidence intervals within actual possible range).

548 Fourth, our definitions of constructs were adapted from the Oxford Living dictionary, which may

549 not always concur with scientific definitions (Dixon et al., 2017). However, we believe that this

550 was not a problem for pain catastrophizing, as this definition was in line with the meaning of the

551 term in the cognitive-behavioral literature on psychopathology. Fifth, the content overlap

552 between pain catastrophizing and pain-related distress deserves further scrutiny. We did not

553 provide a precise definition of pain-related distress, as we believed this term to be self-

554 explanatory. However, this choice may have left the construct ill-defined and overinclusive. For

555 that reason we prefer, as yet, the term pain-related worrying instead of pain-related distress as an

556 alternative term for 'pain catastrophizing'. Sixth, we have not included all pain catastrophizing

557 instruments. Most notably, we excluded the CEQ, which had a different item format from the

558 standard catastrophizing questionnaires. Seventh, we only addressed the content validity of

559 catastrophizing measures, in particular the relevance of items for measuring pain catastrophizing.

560 We did not address their construct validity ('The degree to which the instrument scores are

561 consistent with theory and hypotheses') and their criterion validity ('The degree to which the

562 instrument scores are related to an outcome/criterion') (Mokkink et al., 2010). Eighth, we

563 recognize that the measurement challenges we describe are not unique to pain catastrophizing. In 
564 pain research, this means that the measurement of common constructs such as 'somatization',

565 'kinesiophobia', and 'hypervigilance' will have problems inasmuch as they rely on an objective

566 measure of the actual, a population normative standard, and an expert judgment that the person's

567 perception is extreme. If assessed through decontextualized self-report, they will all be found

568 wanting. Greater scrutiny of these approaches and discussion of alternatives is needed (Cella et

569 al., 2010; Crombez, 2015; Crombez, Beirens, Van Damme, Eccleston, \& Fontaine, 2009;

570 Grossman, 2011). So, let's talk...

571

\section{5. Conclusions}

573 Pain catastrophizing, defined as "to view or present pain or pain-related problems as

574 considerably worse than they actually are" is not measured by current self-report questionnaires

575 of pain catastrophizing. It is unlikely that it will ever will. The construct 'pain catastrophizing'

576 requires contextual information, and expert judgment, which cannot be provided by self-report

577 questionnaires. We argue for a person-centered approach, and propose to rename 'pain

578 catastrophizing' measures in line with what is better measured: 'pain-related worrying'.

579

580

\section{Acknowledgements}

581 We thank Jana Bellaert, Lisa Krämer, Caroline Bell, Madeline Gross, Eva Diana Franz and

582 Marina Spezzacatena for their help in the study.

583

584

\section{References}

585 Amtmann, D., Liljenquist, K., Bamer, A., Bocell, F., Jensen, M., Wilson, R., \& Turk, D. (2018). 
587

588

589

590

591

592

593

594

595

596

597

598

599

600

601

602

603

604

605

606

607

608

609

Groups, and Cognitive Interviews. The Patient, 11(1), 107-117.

https://doi.org/10.1007/s40271-017-0269-1

Attridge, N., Crombez, G., Van Ryckeghem, D., Keogh, E., \& Eccleston, C. (2015). The

Experience of Cognitive Intrusion of Pain: scale development and validation. Pain, 156(10), 1978-1990.

Beatty, P. C., \& Willis, G. (2007). Research Synthesis: The Practice of Cognitive Interviewing. Public Opinion Quarterly, 71(2), 287-311. https://doi.org/10.1093/poq/nfm006

Beck, A. T. (1976). Cognitive Therapy and the Emotional Disorders. New York: International Universities Press.

Beck, A. T. (1979). Cognitive therapy of depression. New York: Guilford press.

Bell, C., Johnston, D., Allan, J., Pollard, B., \& Johnston, M. (2017). What do Demand-Control and Effort-Reward work stress questionnaires really measure? A discriminant content validity study of relevance and representativeness of measures. British Journal of Health Psychology, 22(2), 295-329.

Besen, E., Gaines, B., Linton, S. J., \& Shaw, W. S. (2017). The role of pain catastrophizing as a mediator in the work disability process following acute low back pain. Journal of Applied Biobehavioral Research, 22(1), e12085. https://doi.org/10.1111/jabr.12085

Bossuyt, P. M., Reitsma, J. B., Bruns, D. E., Gatsonis, C. A., Glasziou, P. P., Irwig, L., ... Cohen, J. F. (2015). STARD 2015: an updated list of essential items for reporting diagnostic accuracy studies. BMJ : British Medical Journal, 351.

Burns, J. W., Day, M. A., \& Thorn, B. E. (2012). Is reduction in pain catastrophizing a therapeutic mechanism specific to cognitive-behavioral therapy for chronic pain? Translational Behavioral Medicine, 2(1), 22-29. http://dx.doi.org/10.1007/s13142-011- 
610 0086-3

611 Burns, J. W., Kubilus, A., Bruehl, S., Harden, R. N., \& Lofland, K. (2003). Do changes in

612 cognitive factors influence outcome following multidisciplinary treatment for chronic pain?

613 A cross-lagged panel analysis. Journal of Consulting and Clinical Psychology, 71(1), 81-

614 91. https://doi.org/10.1037/0022-006X.71.1.81

615 Butler, R. W., Damarin, F. L., Beaulieu, C., Schwebel, A. I., \& Thorn, B. E. (1989). Assessing

616 Cognitive Coping Strategies for Acute Postsurgical Pain. Psychological Assessment, 1(1),

617 41-45. https://doi.org/10.1037/1040-3590.1.1.41

618 Cella, D., Riley, W., Stone, A., Rothrock, N., Reeve, B., Yount, S., ... Hays, R. (2010). The

619 Patient-Reported Outcomes Measurement Information System (PROMIS) developed and 620 tested its first wave of adult self-reported health outcome item banks: 2005-2008. Journal $621 \quad$ of Clinical Epidemiology, 63(11), 1179-1194.

622 https://doi.org/https://doi.org/10.1016/j.jclinepi.2010.04.011

623 Clark, D. M. (1986). A cognitive approach to panic. Behaviour Research and Therapy, 24(4),

$624 \quad 461-470$.

625 Crombez, G. (2015). About stagnation and the emperor's new clothes. The Journal of Headache 626 and Pain, 16(1), 3. https://doi.org/10.1186/1129-2377-16-3

627 Crombez, G., Beirens, K., Van Damme, S., Eccleston, C., \& Fontaine, J. (2009). The unbearable 628 lightness of somatisation: A systematic review of the concept of somatisation in empirical 629 studies of pain. Pain, 145(1), 31-35.

630 Davey, G. C. L., \& Levy, S. (1998). Catastrophic worrying: Personal inadequacy and a 631 perseverative iterative style as features of the catastrophizing process. Journal of Abnormal 632 Psychology, 107(4), 576-586. https://doi.org/10.1037/0021-843X.107.4.576 
633 De Ruddere, L., \& Craig, K. D. (2016). Understanding stigma and chronic pain: a-state-of-the-art $634 \quad$ review. Pain, 157(8), 1607-1610.

635 DeWalt, D. A., Rothrock, N., Yount, S., Stone, A. A., \& Group, P. C. (2007). Evaluation of item 636 candidates: the PROMIS qualitative item review. Medical Care, 45(5 Suppl 1), S12-S21. 637 https://doi.org/10.1097/01.mlr.0000254567.79743.e2

638 Dixon, D \& Johnston, M (2019). Content validity of measures of theoretical constructs in health 639 psychology: Discriminant content validity is needed. British Journal of Health

640 Psychology, 24, 477-484. DOI:10.1111/bjhp.12373

641 Dixon, D., Pollard, B., \& Johnston, M. (2007). What does the chronic pain grade questionnaire 642 measure? Pain, 130(3), 249-253. https://doi.org/10.1016/j.pain.2006.12.004

643 Eccleston, C., \& Crombez, G. (2017). Advancing psychological therapies for chronic pain. $644 \quad$ F1000Research, 6, 461.

645 Eccleston, C., Fisher, E. A., Vervoort, T., \& Crombez, G. (2012). Worry and catastrophizing 646 about pain in youth: A reappraisal. Pain, 153(8), 1560-1562.

647 https://doi.org/10.1016/j.pain.2012.02.039

648 Edwards, R. R., Cahalan, C., Mensing, G., Smith, M., \& Haythornthwaite, J. A. (2011). Pain, 649 catastrophizing, and depression in the rheumatic diseases. Nature Reviews Rheumatology, 7 , 650 216-224. https://doi.org/10.1038/nrrheum.2011.2

651 Ellis, A. (1962). Reason and emotion in psychotherapy. New York: Lyle Stuart.

652 Fadyl, J., \& McPherson, K. (2008). Return to Work After Injury: A Review of Evidence 653 Regarding Expectations and Injury Perceptions, and their Influence on Outcome. Journal of 654 Occupational Rehabilitation, 18(4), 362-374. https://doi.org/10.1007/s10926-008-9153-0

655 Flink, I. L., Boersma, K., \& Linton, S. J. (2013). Pain Catastrophizing as Repetitive Negative 
656

657

658

659

660

661

662

663

664

665

666

667

668

669

670

671

672

673 Goubert, L., Crombez, G., \& Van Damme, S. (2004). The role of neuroticism, pain

674

675

676

677

678

Thinking: A Development of the Conceptualization. Cognitive Behaviour Therapy, 42(3), 215-223. https://doi.org/10.1080/16506073.2013.769621

Flor, H., Behle, D. J., \& Birbaumer, N. (1993). Assessment of Pain-Related Cognitions. Behaviour Research and Therapy, 31(1), 63-73.

Fried, E. I. (2017). The 52 symptoms of major depression: Lack of content overlap among seven common depression scales. Journal of Affective Disorders, 208, 191-197. https://doi.org/https://doi.org/10.1016/j.jad.2016.10.019

Gellatly, R., \& Beck, A. T. (2016). Catastrophic Thinking: A Transdiagnostic Process Across Psychiatric Disorders. Cognitive Therapy and Research, 40(4), 441-452. https://doi.org/10.1007/s10608-016-9763-3

Goubert, L., Crombez, G., \& Danneels, L. (2005). The reluctance to generalize corrective experiences in chronic low back pain patients: a questionnaire study of dysfunctional cognitions. Behaviour Research and Therapy, 43(8), 1055-1067. https://doi.org/https://doi.org/10.1016/j.brat.2004.07.005

Goubert, L., Crombez, G., \& De Bourdeaudhuij, I. (2004) Low back pain, disability and back pain myths in a community sample: prevalence and interrelationships. European Journal of Pain, 8, 385-394. catastrophizing and pain-related fear in vigilance to pain: A structural equations approach. Pain, 107(3), 234-241. https://doi.org/10.1016/j.pain.2003.11.005

Grossman, P. (2011). Defining mindfulness by how poorly I think I pay attention during everyday awareness and other intractable problems for psychology's (re)invention of mindfulness: Comment on Brown et al. (2011). Psychological Assessment, 23, 1034-1040. 
https://doi.org/10.1037/a0022713

680 Harvey, A. G., \& Greenall, E. (2003). Catastrophic worry in primary insomnia. Journal of

681 Behavior Therapy and Experimental Psychiatry, 34(1), 11-23.

682 https://doi.org/https://doi.org/10.1016/S0005-7916(03)00003-X

683 Hasenbring, M. I., Hallner, D., \& Rusu, A. C. (2009). Fear-avoidance- and endurance-related

684 responses to pain: Development and validation of the Avoidance-Endurance Questionnaire

685 (AEQ). European Journal of Pain, 13(6), 620-628.

$686 \quad$ https://doi.org/10.1016/j.ejpain.2008.11.001

687 Hirsh, A. T., George, S. Z., Riley, J. L., \& Robinson, M. E. (2007). An evaluation of the

688 measurement of pain catastrophizing by the coping strategies questionnaire. European

689 Journal of Pain, 11(1), 75-81. https://doi.org/10.1016/j.ejpain.2005.12.010

690 Illari, P., \& Russo, F. (2014). Causality: Philosophical theory meets scientific practice. Oxford:

$691 \quad$ Oxford University Press.

692 Jensen, M. P., Turner, J. A., \& Romano, J. M. (2001). Changes in beliefs, catastrophizing, and

693 coping are associated with improvement in multidisciplinary pain treatment. Journal of

694 Consulting and Clinical Psychology, 69, 655-662. https://doi.org/10.1037/0022-

$695 \quad 006 X .69 .4 .655$

696 Johnston, M., Dixon, D., Hart, J., Glidewell, L., Schröder, C., \& Pollard, B. (2014). Discriminant

697 content validity: A quantitative methodology for assessing content of theory-based

698 measures, with illustrative applications. British Journal of Health Psychology, 19(2), 240-

699 257. https://doi.org/10.1111/bjhp.12095

700 Keefe, F. J., Rumble, M. E., Scipio, C. D., Giordano, L. A., \& Perri, L. C. M. (2004).

701 Psychological aspects of persistent pain: Current state of the science. Journal of Pain, 5(4), 
702

703

704

705

706

707

708

709

710

711

712

713

714

715

716

717

718

719

720

721

722

723

724

195-211. https://doi.org/10.1016/j.jpain.2004.02.576

Kerns, R. D., Turk, D., \& Rudy, T. E. (1985). The West Haven-Yale Multidimensional Pain Inventory (WHYMPI). Pain, 23(4), 345-356.

Kirshner, B., \& Guyatt, G. (1985). A methodological framework for assessing health indices. Journal of Chronic Diseases, 38(1), 27-36.

Kraaimaat, F. W., Bakker, A. \& Evers, A. W. M. (1997). Pain-coping strategies in chronic pain patients: the development of the Pain Coping Inventory (PCI). Gedragstherapie, 30, 185201.

Lauwerier, E., Caes, L., Van Damme, S., Goubert, L., Rosseel, Y., \& Crombez, G. (2015). Acceptance: What's in a name? A content analysis of acceptance instruments in individuals with chronic pain. Journal of Pain, 16(4), 306-317. https://doi.org/10.1016/j.jpain.2015.01.001

Lefebvre, M. F. (1981). Cognitive Distortion and Cognitive Errors in Depressed Psychiatric and Low Back Pain Patients Depression scale elevations in the profiles of. Journal of Consulting and Clinical Psychology, 49(4), 517-525.

Lewis, G. N., Rice, D. A., McNair, P. J., \& Kluger, M. (2015). Predictors of persistent pain after total knee arthroplasty: a systematic review and meta-analysis. British Journal of Anaesthesia, 114(4), 551-561. https://doi.org/https://doi.org/10.1093/bja/aeu441

Lilienfeld, S. O., Pydych, A. L., Lynn, S. J., Latzman, R. D., \& Waldman, I. D. (2017). 50 Differences That Make a Difference: A Compendium of Frequently Confused Term Pairs in Psychology. Frontiers in Education, 2, 37. https://www.frontiersin.org/article/10.3389/feduc.2017.00037

Linton, S. J. (2013). A Transdiagnostic Approach to Pain and Emotion. Journal of Applied 
726

727

728

729

730

731

732

733

734

735

736

737

738

739

740

741

742

743

744

745

746

747

Magasi, S., Ryan, G., Revicki, D., Lenderking, W., Hays, R. D., Brod, M., .. Cella, D. (2012). Content validity of patient-reported outcome measures: perspectives from a PROMIS meeting. Quality of Life Research, 21(5), 739-746.

McCracken, L. M. (1997). “Attention” to pain in persons with chronic pain: a behavioral approach. Behavior Therapy, 28(2), 271-284.

Meade, A. W., \& Craig, S. B. (2012). Identifying careless responses in survey data. Psychological Methods, 17(3), 437-455.

Mokkink, L. B., Terwee, C. B., Patrick, D. L., Alonso, J., Stratford, P. W., Knol, D. L., ... de Vet, H. C. W. (2010). The COSMIN study reached international consensus on taxonomy, terminology, and definitions of measurement properties for health-related patient-reported outcomes. Journal of Clinical Epidemiology, 63(7), 737-745.

https://doi.org/https://doi.org/10.1016/j.jclinepi.2010.02.006

Neblett, R. (2017). Pain catastrophizing: An historical perspective. Journal of Applied Biobehavioral Research, 22(1), e12086. https://doi.org/10.1111/jabr.12086

Oppenheimer, D. M., Meyvis, T., \& Davidenko, N. (2009). Instructional manipulation checks: Detecting satisficing to increase statistical power. Journal of Experimental Social Psychology, 45(4), 867-872.

Peer, E., Brandimarte, L., Samat, S., \& Acquisti, A. (2017). Beyond the Turk: Alternative platforms for crowdsourcing behavioral research. Journal of Experimental Social Psychology, 70, 153-163. https://doi.org/https://doi.org/10.1016/j.jesp.2017.01.006

Peerdeman, K. J., van Laarhoven, A. I. M., Peters, M. L., \& Evers, A. W. M. (2016). An integrative review of the influence of expectancies on pain. Frontiers in Psychology, 7, 
748

749 Quartana, P. J., Campbell, C. M., \& Edwards, R. R. (2009). Pain catastrophizing : a critical

750 review. Expert Review Neurotherapeutics, 9(5), 745-758.

$751 \quad$ https://doi.org/10.1586/ERN.09.34.Pain

R Core Team. (2019). R: A language and environment for statistical computing. R Foundation

753

754

755

756

757

758

759

760

761

762

763

764

765

766

767

768

769

770

for Statistical Computing. Vienna, Austria. http://www.r-project.org

Rode, S., Salkovskis, P. M., \& Jack, T. (2001). An experimental study of attention, labelling and memory in people suffering from chronic pain. Pain, 94(2), 193-203.

Rosenstiel, A. K., \& Keefe, F. J. (1983). The use of coping strategies in chronic low back pain patients: Relationship to patient characteristics and current adjustment. Pain, 17(1), 33-44.

Sakamoto, Y., Ishiguro, M., \& Kitagawa, G. (1986). Akaike information criterion statistics. Tokyo: KTK Scientific Publishers.

Salkovskis, P. M., \& Clark, D. M. (1993). Panic disorder and hypochondriasis. Advances in Behaviour Research and Therapy, 15(1), 23-48.

Smeets, R. J. E. M., Vlaeyen, J. W. S., Kester, A. D. M., \& Knottnerus, J. A. (2006). Reduction of Pain Catastrophizing Mediates the Outcome of Both Physical and Cognitive-Behavioral Treatment in Chronic Low Back Pain. The Journal of Pain, 7(4), 261-271. https://doi.org/https://doi.org/10.1016/j.jpain.2005.10.011

Sobol-Kwapinska, M., Bąbel, P., Plotek, W., \& Stelcer, B. (2016). Psychological correlates of acute postsurgical pain: A systematic review and meta-analysis. European Journal of Pain, 20(10), 1573-1586. https://doi.org/10.1002/ejp.886

Sullivan, M., Bishop, S. R., \& Pivik, J. (1995). The Pain Catastrophizing Scale: Development and validation. Psychological Assessment, 7, 524-532. https://doi.org/10.1037/1040- 
772 Sullivan, M., Thorn, B., Haythornthwaite, J. A., Keefe, F., Martin, M., Bradley, L. A., \&

773 Lefebvre, J. C. (2001). Theoretical perspectives on the relation between catastrophizing and 774 pain. Clinical Journal of Pain, 17(1), 52-64. https://doi.org/10.1097/00002508-200103000$775 \quad 00008$

776 Terwee, C. B., Bot, S. D. M., de Boer, M. R., van der Windt, D. A. W. M., Knol, D. L., Dekker, 777 J., ... de Vet, H. C. W. (2007). Quality criteria were proposed for measurement properties 778 of health status questionnaires. Journal of Clinical Epidemiology, 60(1), 34-42.

779 https://doi.org/10.1016/j.jclinepi.2006.03.012

780 Turner, J. A., \& Aaron, L. A. (2001). Pain-related catastrophizing: What is it? Clinical Journal 781 of Pain, 17(1), 65-71. https://doi.org/10.1097/00002508-200103000-00009

782 Turner, J. A., Holtzman, S., \& Mancl, L. (2007). Mediators, moderators, and predictors of 783 therapeutic change in cognitive-behavioral therapy for chronic pain. Pain, 127(3), 276-286.

784 Vlaeyen, J. W. S., Geurts, S. M., Kole-Snijders, A. M. J., Schuerman, J. A., Groenman, N. H., \& 785 van Eek, H. (1990). What do chronic pain patients think of their pain? Towards a pain 786 cognition questionnaire. British Journal of Clinical Psychology, 29(4), 383-394.

787 https://doi.org/10.1111/j.2044-8260.1990.tb00901.x

788 Vlaeyen, J. W. S., \& Linton, S. J. (2000). Fear-avoidance and its consequences in chronic 789 musculoskeletal pain: a state of the art. Pain, 85(3), 317-332.

790 Von Korff, M., Dworkin, S. F., \& Le Resche, L. (1990). Graded chronic pain status: an $791 \quad$ epidemiologic evaluation. Pain, 40(3), 279-291.

792 Von Korff, M., Ormel, J., Keefe, F. J., \& Dworkin, S. F. (1992). Grading the severity of chronic 793 pain. Pain, 50, 133-149. 
794 West, B. T., Welch, K. B., \& Galecki, A. T. (2007). Linear mixed models: A practical guide 795 using statistical software. London: Chapman and Hall/CRC.

796 Wheeler, C. H. B., Williams, A. C. C. \& Morley, S. J. (2019). Meta-analysis of the psychometric 797 properties of the Pain Catastrophizing Scale and associations with participant 798 characteristics. Pain, 160(9):1946-1953. doi: 10.1097/j.pain.0000000000001494.

799 Wideman, T. H., Adams, H., \& Sullivan, M. (2009). A prospective sequential analysis of the 800 fear-avoidance model of pain. Pain, 145(1-2), 45-51.

801 https://doi.org/10.1016/j.pain.2009.04.022

802 Wiering, B., Boer, D., \& Delnoij, D. (2017). Patient involvement in the development of patient803 reported outcome measures: a scoping review. Health Expectations, 20(1), 11-23.

$804 \quad$ https://doi.org/10.1111/hex.12442

805 Willis, G. B. (2015). Analysis of the cognitive interview in questionnaire design. Oxford, UK: $806 \quad$ Oxford University Press. 


\section{Table $\mathbf{1}$ (on next page)}

The five highest and lowest scoring pain catastrophizing items across pain catastrophizing measures.

$\mathrm{mu}=$ estimated mean in the population, $\mathrm{Cl}=95 \%$ confidence interval, $* \mathrm{p}<0.05$, indicating a significant difference in score with the construct 'pain catastrophizing' 


\begin{tabular}{|c|c|c|c|c|c|c|}
\hline & ITEM & MEASURE & $\begin{array}{c}\text { PAIN } \\
\text { CATASTROPHIZING } \\
\hat{\mu}[\mathrm{Cl}]\end{array}$ & $\begin{array}{c}\text { PAIN-RELATED } \\
\text { DISABILITY } \\
\hat{\mu}[\mathrm{CI}]\end{array}$ & $\begin{array}{l}\text { PAIN-RELATED } \\
\text { DISTRESS } \\
\hat{\mu}[\mathrm{Cl}] \\
\end{array}$ & PAIN SE \\
\hline \multirow[t]{5}{*}{$\begin{array}{l}\text { BEST } \\
\text { ITEMS }\end{array}$} & $\begin{array}{l}\text { When I'm in pain, it's terrible } \\
\text { and I think it's never going to } \\
\text { get any better" }\end{array}$ & $\mathrm{PCS} / \mathrm{CSQ}$ & $\begin{array}{c}7.41 \\
{[5.36 \text { to } 9.44]}\end{array}$ & $\begin{array}{c}-3.56^{*} \\
{[-6.39 \text { to }-0.75]}\end{array}$ & $\begin{array}{c}7.21 \\
{[5.41 \text { to } 9.00]}\end{array}$ & $\begin{array}{r}4 . \\
{[2.14 \mathrm{t}}\end{array}$ \\
\hline & This will never end & PRSS & $\begin{array}{c}6.58 \\
{[4.51 \text { to } 8.64]}\end{array}$ & $\begin{array}{c}-4.61^{*} \\
{[-7.23 \text { to }-2.00]}\end{array}$ & $\begin{array}{c}5.74 \\
{[3.23 \text { to } 8.24]}\end{array}$ & $\begin{array}{r}-0.7 \\
{[-3.88 t}\end{array}$ \\
\hline & I can't go on anymore & PRSS & $\begin{array}{c}5.92 \\
{[3.60 \text { to } 8.24]}\end{array}$ & $\begin{array}{c}2.58 \\
{[-0.33 \text { to } 5.48]}\end{array}$ & $\begin{array}{c}8.05^{*} \\
{[6.33 \text { to } 9.76]}\end{array}$ & {$[0.66 \mathrm{t}$} \\
\hline & $\begin{array}{l}\text { When I feel pain, I feel my life } \\
\text { isn't worth living }\end{array}$ & $\mathrm{CSQ}$ & $\begin{array}{c}5.90 \\
{[4.64 \text { to } 7.15]}\end{array}$ & $\begin{array}{c}-2.21^{*} \\
{[-3.73 \text { to }-0.67]}\end{array}$ & $\begin{array}{c}8.28^{*} \\
\text { [7.58 to } 8.99]\end{array}$ & $\begin{array}{r}0.5 \\
{[-1.11 \mathrm{t}}\end{array}$ \\
\hline & $\begin{array}{l}\text { When I'm in pain, I feel I can't } \\
\text { stand it anymore }\end{array}$ & PCS/CSQ & $\begin{array}{c}5.49 \\
{[3.37 \text { to } 7.62]}\end{array}$ & $\begin{array}{c}-0.49 * \\
{[-3.35 \text { to } 2.34]}\end{array}$ & $\begin{array}{c}6.82 \\
{[5.15 \text { to } 8.46]}\end{array}$ & {$[2.99 \mathrm{t}$} \\
\hline \multirow[t]{5}{*}{$\begin{array}{l}\text { WORST } \\
\text { ITEMS }\end{array}$} & $\begin{array}{l}\text { I need to take some pain } \\
\text { medication }\end{array}$ & PRSS & $\begin{array}{c}-7.06 \\
{[-8.68 \text { to }-5.43]}\end{array}$ & $\begin{array}{c}-3.57^{*} \\
{[-6.49 \text { to }-0.68]}\end{array}$ & $\begin{array}{c}-1.71^{*} \\
{[-4.73 \text { to } 1.30]}\end{array}$ & $\begin{array}{r}2.9 \\
{[-0.02 t}\end{array}$ \\
\hline & $\begin{array}{l}\text { When I'm in pain, I anxiously } \\
\text { want the pain to go away }\end{array}$ & PCS & $\begin{array}{c}-6.54 \\
{[-8.36 \text { to }-4.69]}\end{array}$ & $\begin{array}{c}-6.92 \\
{[-8.85 \text { to }-4.99]}\end{array}$ & $\begin{array}{c}5.61^{*} \\
{[3.03 \text { to } 8.18]}\end{array}$ & $\begin{array}{r}-3.7 \\
{[-6.72 t}\end{array}$ \\
\hline & $\begin{array}{l}\text { I make sure I protect myself } \\
\text { from extra pain }\end{array}$ & PCL & $\begin{array}{c}-5.55 \\
{[-6.64 \text { to }-4.46]}\end{array}$ & $\begin{array}{c}-5.40 \\
{[-6.58 \text { to }-4.21]}\end{array}$ & $\begin{array}{c}-2.46^{*} \\
{[3.98 \text { to }-0.94]}\end{array}$ & $\begin{array}{r}-2.1 \\
{[-3.69 t}\end{array}$ \\
\hline & I think I am always very tense & PCL & $\begin{array}{c}-5.51 \\
{[-7.48 \text { to }-3.54]}\end{array}$ & $\begin{array}{c}-6.04 \\
{[-7.79 \text { to }-4.30]}\end{array}$ & $\begin{array}{c}-0.17^{*} \\
{[-2.96 \text { to } 2.60]}\end{array}$ & $\begin{array}{r}-5 . \\
{[-7.83 t}\end{array}$ \\
\hline & $\begin{array}{l}\text { I am disappointed in myself for } \\
\text { giving in to the pain }\end{array}$ & $\mathrm{PCL}$ & $\begin{array}{c}-4.88 \\
{[-7.33 \text { to }-2.41]}\end{array}$ & $\begin{array}{c}-4.64 \\
{[-7.16 \text { to }-2.15]}\end{array}$ & $\begin{array}{c}4.57^{*} \\
{[1.79 \text { to } 7.35]}\end{array}$ & $\begin{array}{r}-4 . \\
{[-7.33 t}\end{array}$ \\
\hline
\end{tabular}




\section{Figure 1}

Estimates and associated $95 \%$ credibility intervals $(\mathrm{Cl})$ of the relevance score for the $\mathrm{PCl}$ (worry about pain), PVAQ (pain vigilance) and MPI (affective distress; disability; pain severity) on each construct.

The estimate and $\mathrm{Cl}$ for the construct each measure is designed to assess is indicated in black. The estimate and $\mathrm{Cl}$ for the other constructs is depicted in grey. Included scales were (subscales of) the (A) PCI (Pain Cognitions Inventory), (B) PVAQ (Pain Vigilance and Awareness Questionnaire), (C) MPI - affective distress (Multidimensional Pain Inventory), (D) MPI - disability (Multidimensional Pain Inventory).(E) MPI - pain severity (Multidimensional Pain Inventory). 
A

$\mathrm{PCI}$

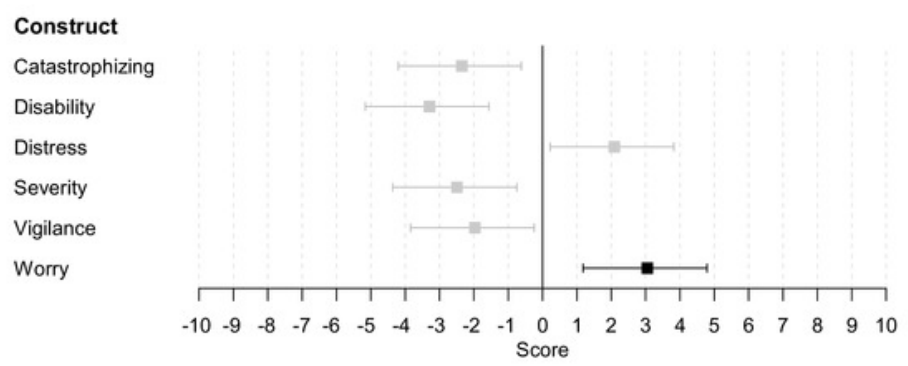

C

MPI - affective distress

Construct

Catastrophizing

Disability

Distress

Severity

Vigilance

Worry

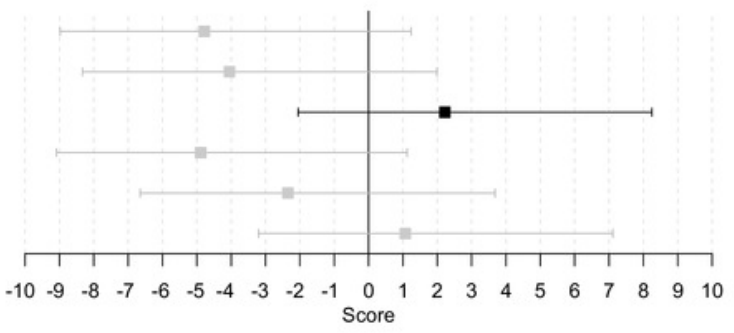

E

MPI - pain severity

Construct

Catastrophizing

Disability

Distress

Severity

Vigilance

Worry

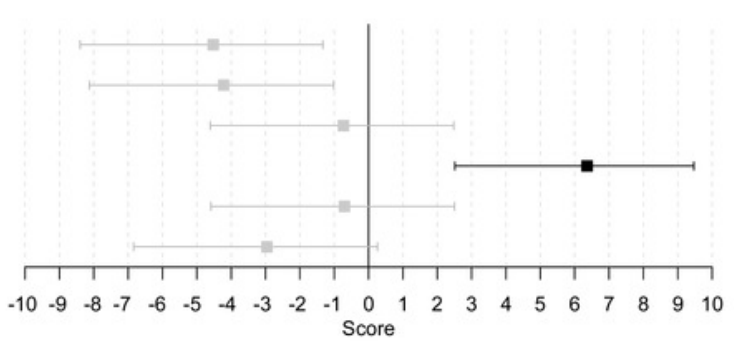

B

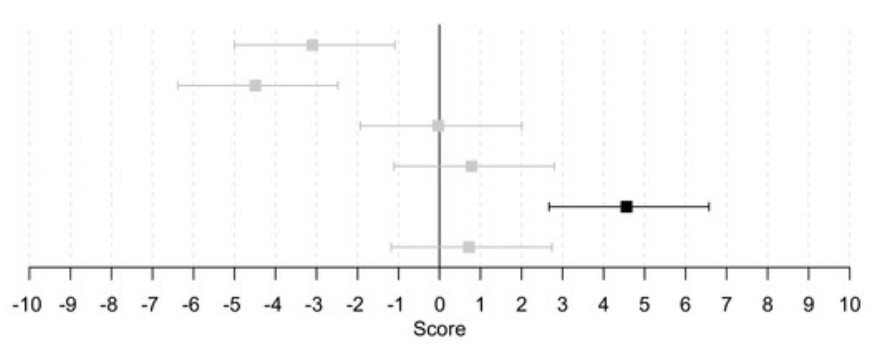

D

MPI - disability

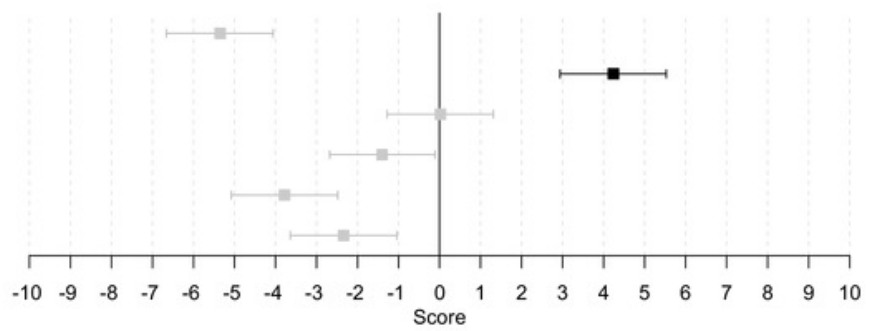


Figure 2

Estimates and associated 95\% credibility intervals of the relevance score for each of the six pain catastrophizing measures on pain catastrophizing.

The six pain catastrophizing measures were (subscales of) the AEQ (Avoidance Endurance Questionnaire), CSQ (Coping Strategies Questionnaire), CCSI (Cognitive Coping Strategies Inventory), PCS (Pain Catastrophizing Scale), PCL (Pain Cognition List), and PRSS (PainRelated Self-Statements Scale).

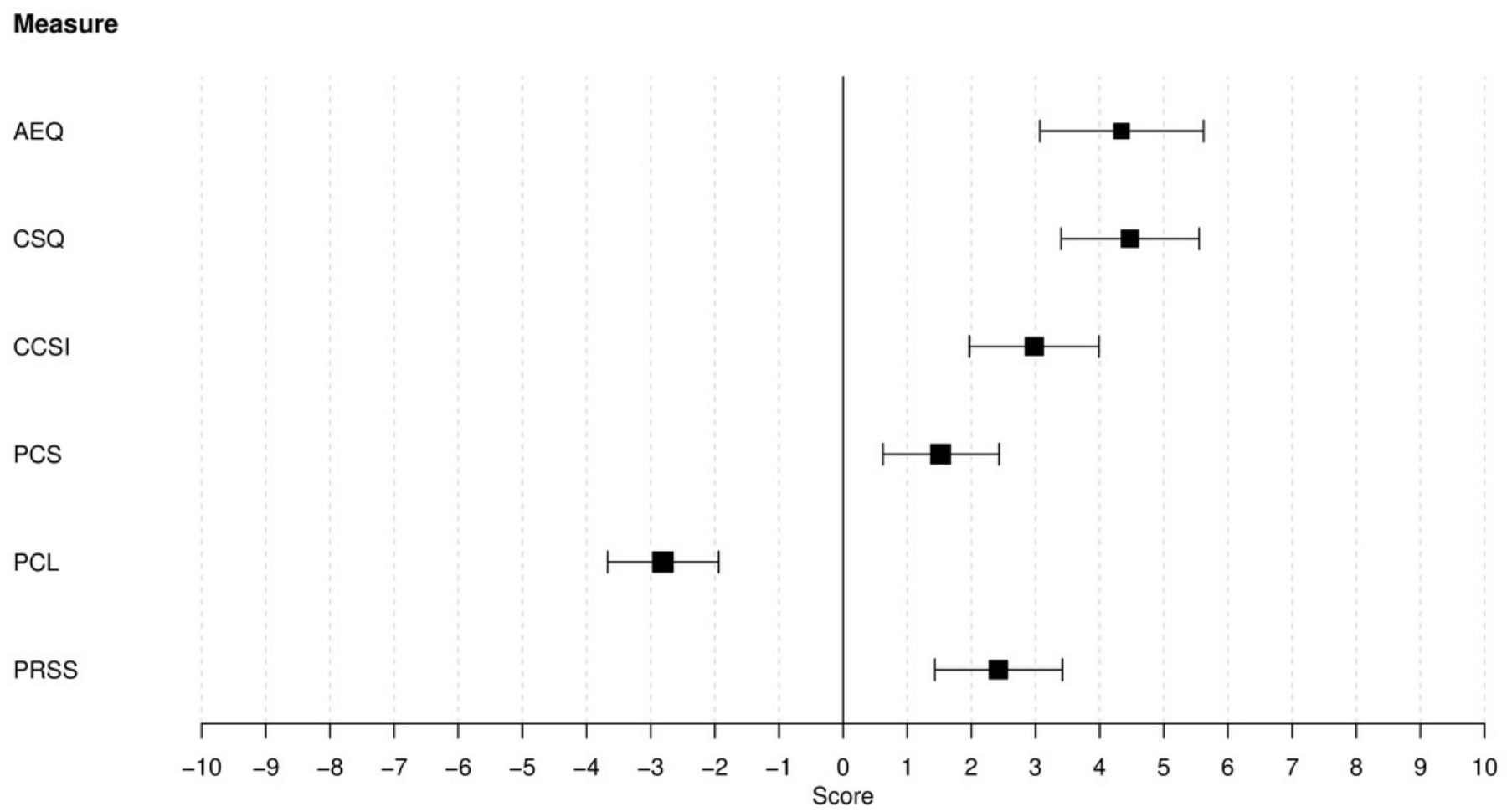




\section{Figure 3}

Estimates and associated 95\% credibility intervals of the relevance score for each of the six pain catastrophizing measures on each construct.

Estimates and associated $95 \%$ credibility intervals of the score of each of the six pain catastrophizing measures on each construct. The estimate and $\mathrm{Cl}$ for the construct each measure is designed to assess is indicated in black. The estimate and $\mathrm{Cl}$ for the other constructs is depicted in grey. The six pain catastrophizing measures were (subscales of) the (A) AEQ (Avoidance Endurance Questionnaire), (B) CSQ (Coping Strategies Questionnaire), (C) CCSI (Cognitive Coping Strategies Inventory), (D) PCL (Pain Cognition List), (E) PCS (Pain Catastrophizing Scale), and (F) PRSS (Pain-Related Self-Statements Scale). 
A

AEQ

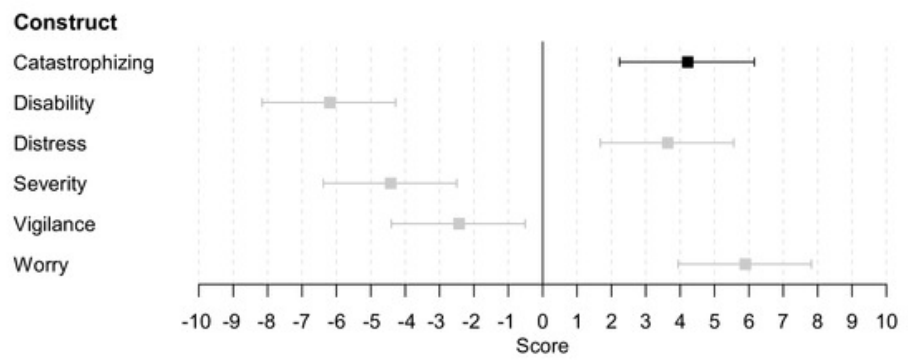

C

Construct

Catastrophizing

Disability

Distress

Severity

Vigilance

Worry

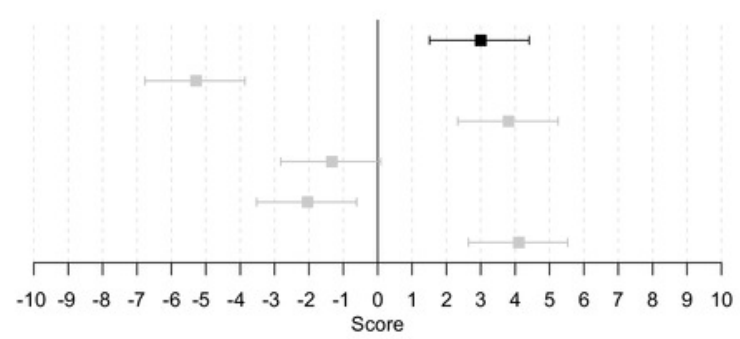

E

PCS

Construct

Catastrophizing

Disability

Distress

Severity

Vigilance

Worry

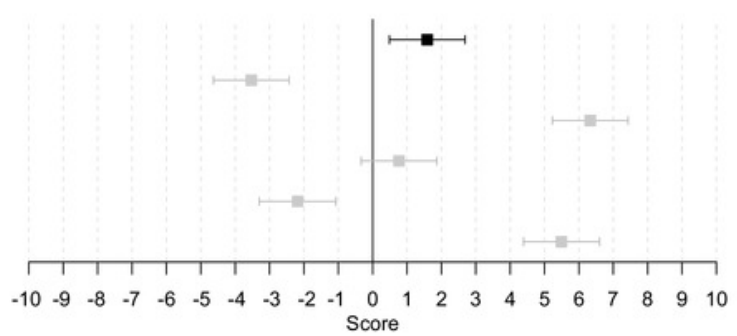

B

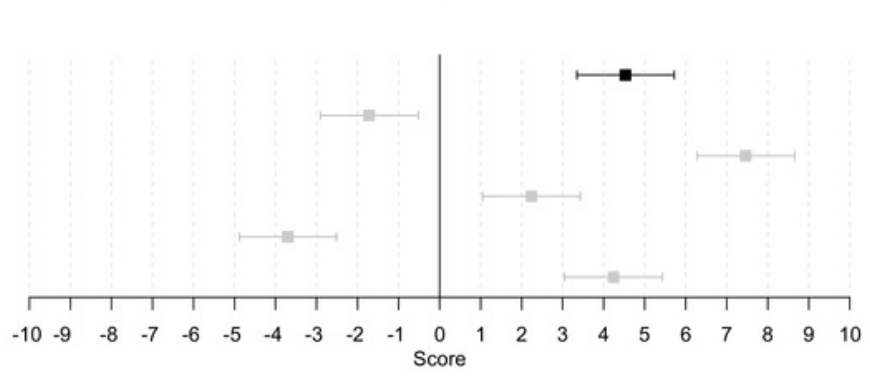

D

PCL

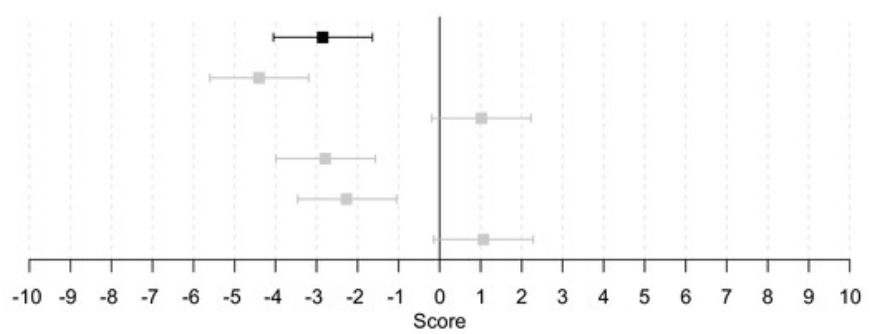

F

PRSS

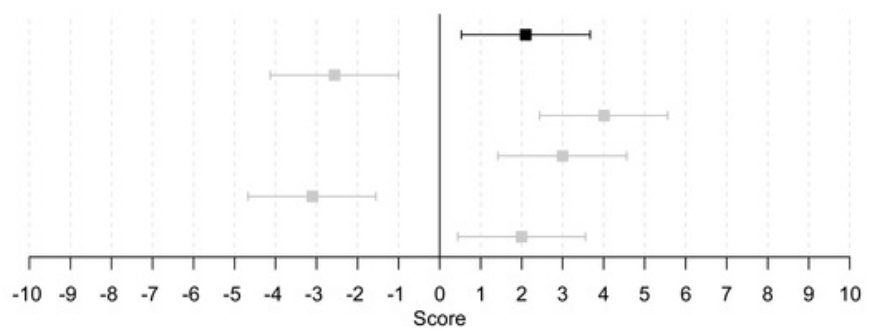

